\title{
Safety, efficacy, and patient acceptability of single- dose fosaprepitant regimen for the prevention of chemotherapy-induced nausea and vomiting
}

This article was published in the following Dove Press journal:

Patient Preference and Adherence

6 May 2013

Number of times this article has been viewed

\section{Luigi Celio \\ Francesca Ricchini \\ Filippo De Braud}

Medical Oncology Unit I, Department of Medical Oncology, Fondazione IRCCS Istituto Nazionale Tumori, Milan, Italy
Correspondence: Luigi Celio Medical Oncology Unit I, Department of Medical Oncology, Fondazione IRCCS Istituto Nazionale Tumori, Via G Venezian I, 20133 Milan, Italy

Tel +39223902597

Fax +39223902149

Email luigi.celio@istitutotumori.mi.it
Abstract: Control of chemotherapy-induced nausea and vomiting (CINV) is a crucial factor in ensuring that patients undergoing cancer chemotherapy can get the full benefit of therapy. Current antiemetic guidelines recommend that the neurokinin-1 receptor (NK-1R) antagonist aprepitant should be used as part of a combination regimen with dexamethasone and a serotonin receptor antagonist for the prevention of CINV in patients receiving highly emetogenic chemotherapy (HEC). Fosaprepitant is a water-soluble $N$-phosphoryl derivative of aprepitant that, when infused, is rapidly metabolized back to an active aprepitant. The existing literature in PubMed about fosaprepitant was screened and selected in order to address the emerging data from two randomized clinical trials evaluating the efficacy and safety of a single-dose fosaprepitant regimen. These phase III trials demonstrated that fosaprepitant given as a single intravenous dose of $150 \mathrm{mg}$ was either noninferior to the conventional 3-day aprepitant or significantly superior to placebo for the prevention of acute and delayed CINV in patients receiving high-dose cisplatin. In both trials, fosaprepitant was well tolerated although more frequent infusion-site adverse events were observed with fosaprepitant. The new dosage regimen of fosaprepitant, therefore, would be an option for CINV control in patients receiving cisplatin-based chemotherapy. The clinical efficacy is consistent with the findings from a time-on-target, positron-emission tomography study evaluating the NK-1R occupancy in the central nervous system (CNS) over 5 days after a single-dose infusion of $150 \mathrm{mg}$ fosaprepitant in healthy participants. The single-dose regimen is capable of blocking more than $90 \%$ of the NK-1Rs in the CNS for at least 48 hours after infusion, which is sufficient to control delayed CINV for 2 to 5 days after HEC. The new dosage regimen of fosaprepitant can provide a simplified treatment option that maintains high protection while ensuring adherence to scheduled antiemetic medication throughout most of the 5-day period encompassing the major risk for CINV.

Keywords: fosaprepitant, neurokinin-1 receptor antagonist, chemotherapy-induced nausea and vomiting

\section{Introduction}

Cytotoxic chemotherapy remains a cornerstone of therapy for most patients with cancer but a high cost, in terms of adverse events and quality of life, is associated with it. ${ }^{1}$ Many chemotherapeutic agents are associated with significant nausea and vomiting, which represent debilitating and feared adverse effects. ${ }^{2}$ Nausea and vomiting can negatively affect a patient's quality of life as well as adherence with scheduled chemotherapy, leading to delay or sometimes to discontinue potentially beneficial treatment regimens. If poorly controlled, these adverse effects can give rise to medical complications, including poor nutrition, weight loss, dehydration, and electrolyte imbalances 
that complicate cancer management. ${ }^{3}$ Inadequate emesis control may also lead to anticipatory nausea and vomiting, which are more difficult to control than acute or delayed symptoms. ${ }^{4}$ Therefore, control of chemotherapy-induced nausea and vomiting (CINV) is a crucial factor in ensuring that patients undergoing cancer chemotherapy can get the full benefit of therapy.

Both patient-specific and chemotherapy-related risk factors are known to increase the risk for developing CINV. Patient-specific risk factors include sex (CINV is more likely to occur in women), age (patients younger than 50 years are more likely to experience CINV), history of light or no alcohol consumption, prior history of CINV, emesis during pregnancy, history of motion sickness, and anxiety. ${ }^{5}$ The individual patient risk for CINV is also largely influenced by the intrinsic emetogenicity (based on dose, route, schedule, and rate of administration) of a chemotherapeutic agent. ${ }^{2}$ The chemotherapeutic drugs have been classified into four emetic risk categories: high ( $>90 \%$ of patients will experience emesis without prophylaxis), moderate $(30 \%-90 \%$ of patients will experience emesis without prophylaxis), low (10\%-30\% of patients will experience emesis without prophylaxis), and minimal ( $<10 \%$ of patients will experience emesis without prophylaxis). ${ }^{5}$ Cisplatin represents the main example of a chemotherapeutic drug with a high emetogenic potential; doses greater than $50 \mathrm{mg} / \mathrm{m}^{2}$ cause CINV in more than $90 \%$ of patients if no prophylaxis is used.

CINV can be historically classified under three distinct categories: acute onset, delayed onset, and anticipatory. ${ }^{3}$ Acute CINV occurs within the first 24 hours following chemotherapy administration, whereas delayed CINV is arbitrarily defined as nausea and vomiting occurring after the first 24 hours and up to 120 hours after chemotherapy is given. Delayed CINV can often be worse than acute symptoms because it is more likely to occur in a patient's home, away from immediate medical assistance. Anticipatory CINV is a learned response that arises secondary to a history of poorly controlled nausea and vomiting during prior chemotherapy. ${ }^{4}$ A distinct clinical syndrome that may develop with administration of chemotherapy is known as breakthrough CINV that occurs when, despite the best prophylaxis used, the patient still experiences nausea and vomiting. ${ }^{3}$

Multiple neurotransmitters have been established as important mediators in CINV. ${ }^{2}$ There is no single neurotransmitter responsible for all forms of CINV but physiologic differences exist in the pathways involved in the acute and delayed symptoms. The critical role of serotonin (5-hydroxytryptamine, 5-HT), a neurotransmitter synthesized in the central nervous system (CNS) and in enterochromaffin cells of the gastrointestinal tract (GIT), and the 5-HT type- 3 receptor $\left(5-\mathrm{HT}_{3} \mathrm{R}\right)$ in acute $\mathrm{CINV}$ is supported by preclinical models and clinical trials. ${ }^{6}$ Substance P (SP), a neuropeptide of the tachykinin family, via binding to the neurokinin-1 receptor (NK-1R) has been assumed to be a more relevant neurotransmitter in delayed CINV. ${ }^{7}$ SP released from enterochromaffin cells binds to NK-1Rs in the CNS and GIT, which mediates the vomiting reflex. ${ }^{8}$ In the light of the multiple pathways involved in the pathophysiology of CINV, antiemetic therapy incorporating a combination of several agents, which modulate neurotransmitter receptors in the CNS and GIT, should be administered before initial chemotherapy to prevent the development of both acute and delayed CINV. ${ }^{5}$

Corticosteroids (eg, dexamethasone) and 5- $\mathrm{HT}_{3} \mathrm{R}$ antagonists have been the mainstay of antiemetic prophylaxis in patients receiving highly and moderately emetogenic chemotherapy (HEC and MEC). The 5- $\mathrm{HT}_{3} \mathrm{R}$ antagonists combined with dexamethasone dramatically improved the control of acute CINV caused by HEC regimens. ${ }^{9}{ }^{910}$ A more recent development has been the NK-1R antagonist class, which targets the SP activity at NK-1Rs in the CNS and is more effective against delayed CINV. Well-designed phase III trials demonstrated that the addition of oral aprepitant to ondansetron plus dexamethasone increases the proportion of patients achieving complete response (CR; defined as no vomiting and no rescue antiemetics) by 9\%-21\% during the first 120 hours following chemotherapy containing cisplatin or the combination of an anthracycline plus cyclophosphamide (AC). ${ }^{11-13}$ In 2003, the potent and selective SP antagonist, aprepitant became the first and still remains the only NK-1R antagonist clinically available for the control of acute and delayed CINV in cancer patients. ${ }^{14-16}$ The currently approved 3-day dosing regimen for orally administered aprepitant is $125 \mathrm{mg}$ before chemotherapy initiation followed by $80 \mathrm{mg}$ on days 2 and 3 . It has been demonstrated that the maximal antiemetic efficacy of aprepitant is associated with greater than $90 \%$ occupancy of NK-1Rs in the human CNS and this high level of occupancy would be achieved with the conventional 3-day oral regimen. ${ }^{17}$ The approval of fosaprepitant dimeglumine (hereafter referred to as fosaprepitant), an intravenous prodrug of aprepitant, increased the delivery options available to oncologists and patients and provided maximum clinical dosing flexibility.

The existing literature in PubMed about fosaprepitant in the prevention of acute and delayed CINV was screened and selected in order to address the emerging data from 
two randomized clinical trials evaluating the efficacy and safety of a single-dose fosaprepitant regimen in patients receiving $\mathrm{HEC}$.

\section{Fosaprepitant as an alternative on day I of a 3-day oral aprepitant: an overview}

Fosaprepitant $\left(\right.$ Emend $^{\circledR}$ for injection, Ivemend ${ }^{\circledR}$, Merck \& Co., Inc, Whitehouse Station, NJ, USA) is a water-soluble $N$-phosphoryl derivative of aprepitant, ${ }^{14}$ which, when infused, is rapidly metabolized back to active aprepitant by ubiquitous phosphatases. ${ }^{18}$ Therefore, the antiemetic efficacy of the intravenous prodrug is attributed entirely to aprepitant. Fosaprepitant also follows the metabolic pathway of aprepitant, which is metabolized in the liver by cytochrome P450 (CYP) enzymes, primarily by CYP3A4. ${ }^{19}$ Since aprepitant is a weak-to-moderate (dose-dependent) inhibitor and inducer of CYP3A4, caution should be taken when administering fosaprepitant/aprepitant with drugs such as corticosteroids that are primarily metabolized by this enzyme because it may result in increases in the area under the plasma concentration-time curve (AUC) of these drugs and of aprepitant itself. ${ }^{20}$ The safety of fosaprepitant was assessed in several phase I clinical trials with approximately 700 participants/patients. ${ }^{21}$ In most of these studies, single doses ranging from 0.2 to $200 \mathrm{mg}$ were administered, and a concentration of $1 \mathrm{mg} / \mathrm{mL}$ infused over 15 to 30 minutes was associated with acceptable venous tolerability.

In the initial development of aprepitant, two phase II trials were conducted with the use of fosaprepitant in patients receiving their first dose of cisplatin. ${ }^{22,23}$ Overall, these early studies involving small numbers of patients receiving no standardized dosages and combinations of antiemetic agents ${ }^{15,16}$ suggested that fosaprepitant could be investigated as an alternative intravenous formulation to oral aprepitant. In 2007, a randomized, open-label, crossover study of 106 healthy participants showed that the $115 \mathrm{mg}$ fosaprepitant dose administered over 15 minutes provides an AUC equivalent to that of the $125 \mathrm{mg}$ oral aprepitant dose on day $1 .{ }^{21}$ In this study fosaprepitant was well tolerated at doses up to $150 \mathrm{mg}$. Another randomized, double-blind, crossover study showed no meaningful increases in QTc intervals in healthy participants receiving a $200 \mathrm{mg}$ dose of fosaprepitant. ${ }^{24} \mathrm{~A}$ recent systematic review with a meta-analysis evaluating the overall impact of NK-1R antagonists on CINV prevention showed that, among patients given aprepitant, 1459 of 2268 (64.3\%) achieved CR versus 977 of 1972 (49.5\%) in the control group during the first 120 hours following chemotherapy initiation (odds ratio [OR] 0.53; $95 \%$ confidence interval [CI]: 0.45 to $0.61 ; P<0.00001) .{ }^{25}$
In 2008, fosaprepitant was approved as a substitution dose (115 mg) for the $125 \mathrm{mg}$ oral capsule of aprepitant on day 1 of a 3-day regimen for the prevention of acute and delayed CINV caused by HEC and MEC.

\section{Focus on the single-dose fosaprepitant regimen for the prevention of CINV Rationale}

During the development of aprepitant, a positron-emission tomography (PET) tracer was developed to assess the NK-1R occupancy by therapeutic doses of aprepitant in the living human CNS. ${ }^{14}$ The findings were important to select the dosing regimen capable of ensuring the lowest aprepitant exposure that produced more than $90 \%$ of NK-1R occupancy in the CNS. ${ }^{17}$ However, daily doses of aprepitant higher than those currently used (up to $375 \mathrm{mg}$ ) were well tolerated, ${ }^{26}$ and a pharmacokinetic study suggested that a single $300 \mathrm{mg}$ dose of aprepitant was capable of maintaining circulating levels over an extended period of time similar to those of the conventional 3-day regimen. ${ }^{27}$ A preliminary investigation of a single-day three-drug regimen consisting of the second-generation $5-\mathrm{HT}_{3} \mathrm{R}$ antagonist palonosetron ( $0.25 \mathrm{mg}$ intravenously) plus dexamethasone ( $20 \mathrm{mg}$ orally) and aprepitant ( $285 \mathrm{mg}$ orally) demonstrated a high degree of efficacy against both acute and delayed CINV caused by MEC. ${ }^{28}$ In addition, a pilot randomized trial of patients who were receiving palonosetron, dexamethasone, and aprepitant for control of CINV caused by HEC, suggested similar efficacy of a 1-day (125 mg orally) and the standard 3-day regimen of aprepitant. ${ }^{29}$ Therefore, phase III trials were designed to evaluate the efficacy, safety, and tolerability of a single $150 \mathrm{mg}$ intravenous dose of fosaprepitant in a regimen not requiring subsequent administration of oral aprepitant on days 2 and 3 after chemotherapy initiation. The dose of fosaprepitant was selected because it is within the range of previously evaluated doses, ${ }^{21}$ and the predicted NK-1R occupancy in the CNS with this dose would exceed $90 \% .{ }^{17}$

\section{Safety}

The safety and tolerability of fosaprepitant have been reported to be similar to those of aprepitant because it is rapidly converted to aprepitant following infusion, without significant tissue distribution of the prodrug. ${ }^{30} \mathrm{~A}$ recent meta-analysis of 17 clinical trials $(n=8740)$ assessing several different NK-1R antagonists analyzed the occurrence of adverse events in the first cycle of chemotherapy. ${ }^{25}$ In this large population (44.5\% of the patients received aprepitant), any grade 
asthenia (OR $=1.23,95 \% \mathrm{CI}: 1.05$ to $1.45 ; P=0.01)$, any grade hiccups $(\mathrm{OR}=1.30,95 \% \mathrm{CI}: 1.03$ to $1.64 ; P=0.03)$, and severe infection, as defined by the National Cancer Institute Common Terminology Criteria for Adverse Events CTCAEv3.0, $(\mathrm{OR}=3.10,95 \% \mathrm{CI}: 1.69$ to $5.67 ; P<0.001)$ occurred more frequently among patients in the NK-1R antagonist group. Any grade constipation ( $\mathrm{OR}=0.79,95 \%$ CI: 0.69 to $0.90 ; P<0.001)$ was more common in the control group, whereas the use of NK-1R antagonists was not associated with an increase in the risk of diarrhea $(\mathrm{OR}=1.06,95 \%$ CI: 0.87 to $1.30 ; P=0.56)$. The association between NK-1R antagonists and severe infection needs a few comments. This analysis was derived from only three trials of aprepitant, but supported the finding of a significant increase (from $2 \%$ to $6 \%$ ) in the risk of severe infection among patients who received the NK-1R antagonist. ${ }^{12,26,31}$ Although aprepitant may increase the plasma concentration of dexamethasone due to the CYP3A4 inhibitory effect of the drug, ${ }^{20}$ there were similar frequencies of severe infection among patients who did not receive a decreased dexamethasone dose ${ }^{26}$ and those who did. ${ }^{12,31}$ Aprepitant can also increase the exposure to chemotherapy agents metabolized by CYP3A4, but the rate of febrile neutropenia or any other hematological toxicity was not more frequent among patients who received NK-1R antagonists compared with those in the control group. ${ }^{25}$

The incidence of the most regularly encountered adverse events, except for infusion-site reactions, in two recent phase III trials evaluating the single-dose fosaprepitant regimen (150 $\mathrm{mg}$ on day 1 ) are listed in Table 1 . In the Grunberg study, the adverse event profile for the fosaprepitant group was consistent with that observed in patients receiving the conventional 3 -day aprepitant. ${ }^{32}$ There was a higher incidence of asthenia and anorexia in patients treated with aprepitant compared with patients treated with fosaprepitant. No difference in the overall incidence of infections was observed between treatment groups, but urinary tract infections were more common with fosaprepitant. In the Saito study, the overall incidence of drug-related adverse events did not differ significantly between the fosaprepitant group and the control group including placebo (26\% vs $28 \% ; P=0.80) .{ }^{33}$ There was no significant difference in the incidence of serious drug-related adverse events $(0.6 \%$ vs $0.6 \% ; P=0.98$ ) between treatment groups. It also should be noted that $44 \%$ of the patients in the fosaprepitant group and $37 \%$ in the control group received chemotherapy agents metabolized by CYP3A4. However, the incidence of chemotherapy-related hematological toxicity including febrile neutropenia (fosaprepitant, 2\%; placebo, 3.5\%), neutropenia (fosaprepitant, 51\%; placebo, 54\%), and thrombocytopenia (fosaprepitant, 33\%; placebo, 37\%) was similar between treatment groups. ${ }^{33}$

In both studies, the patients were also assessed for the occurrence of infusion-site reactions (Table 2). In the Grunberg study, there were significantly more cases of infusion-associated thrombophlebitis with fosaprepitant than with aprepitant $(0.8 \%$ vs $0.1 \% ; P=0.005) .{ }^{32}$ Of the nine cases of thrombophlebitis reported in patients receiving fosaprepitant, only three were considered related to the study drug according to investigator assessment. In the Saito study, the overall incidence of infusion-related adverse events was significantly higher in the fosaprepitant group than in the control group (24\% vs $12 \% ; P=0.006) .{ }^{33}$ Although severe events were not observed, a slight increase in the incidence of moderate-grade adverse events was noted for patients in the fosaprepitant group compared with patients in the control group ( $3 \%$ vs $2 \% ; P=0.32)$.

\section{Efficacy}

Two multicenter, randomized, double-blind, phase III trials have recently investigated the antiemetic efficacy of a singledose fosaprepitant regimen in patients scheduled to receive high-dose cisplatin ( $\geq 70 \mathrm{mg} / \mathrm{m}^{2}$ ) (Table 3 ). The Grunberg study including 2,322 patients compared fosaprepitant (150 mg on day 1) to the conventional 3-day aprepitant, both in combination with ondansetron (32 $\mathrm{mg}$ intravenously on day 1) plus dexamethasone. ${ }^{32}$ Concomitant dexamethasone

Table I Adverse events in phase III clinical trials with single-dose fosaprepitant regimen in patients receiving cisplatin

\begin{tabular}{|c|c|c|c|c|c|c|c|c|c|c|}
\hline \multirow[t]{2}{*}{ Study (year) } & \multirow[t]{2}{*}{$\mathbf{N}$} & \multirow[t]{2}{*}{ Antiemetics } & \multicolumn{8}{|c|}{ Incidence of adverse events, any grade ${ }^{a}(\%)$} \\
\hline & & & Total & Anorexia & Constipation & Diarrhea & Vomiting & Asthenia & Nausea & Hiccups \\
\hline Grunberg et al & 2,322 & $D+O+F O S$ & NR & 7 & 11 & 8 & 7 & 9 & 6 & 6 \\
\hline$(2011)^{32}$ & & $D+O+A P R$ & NR & 9 & 10 & 9 & 6 & 12 & 7 & 6 \\
\hline Saito et al & 347 & $D+G+F O S$ & 26 & $52^{\mathrm{b}}$ & 40 & NR & NR & $29^{c}$ & 44 & 32 \\
\hline$(2012)^{33}$ & & $D+G+P L A$ & 28 & $48^{\mathrm{b}}$ & 33 & NR & NR & $27^{c}$ & 44 & 35 \\
\hline
\end{tabular}

Notes: ${ }^{a}$ Categorized by using the National Cancer Institute Common Terminology Criteria for Adverse Events, version 3.0; ${ }^{\mathrm{p} p e r c e n t a g e}$ of patients complaining of reduced appetite; 'percentage of patients complaining of malaise.

Abbreviations: D, dexamethasone; O, ondansetron; FOS, fosaprepitant; APR, aprepitant; G, granisetron; PLA, placebo; NR, not reported. 


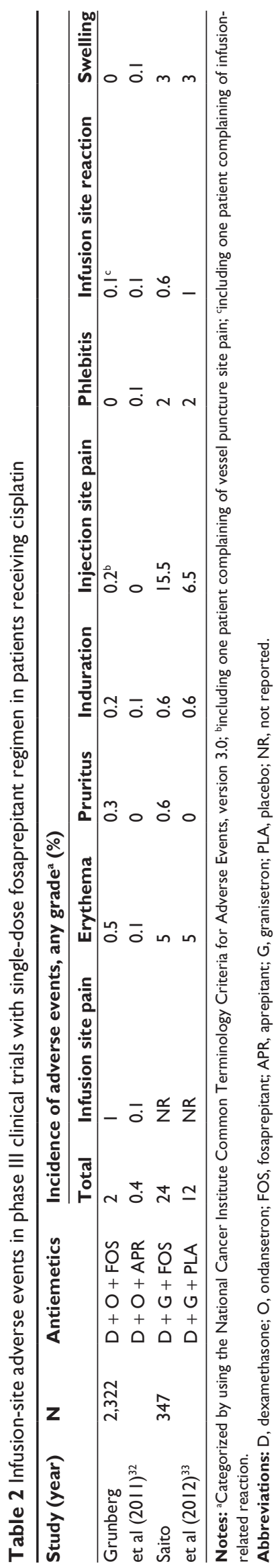

was administered as a $12 \mathrm{mg}$ oral dose on day 1 followed by either $8 \mathrm{mg}$ orally on day 2 and $8 \mathrm{mg}$ twice daily on days 3 and 4 (for fosaprepitant group) or $8 \mathrm{mg}$ orally on days $2-4$ (for aprepitant group). The primary end-point was CR during the overall phase (days 1-5 post-chemotherapy). The study was designed as a noninferiority study with an expected CR rate of $67.7 \%$ in each treatment group and a noninferiority margin of -7 percentage points. In the fosaprepitant group, $71.9 \%$ of the patients achieved CR compared with $72.3 \%$ in the aprepitant group, a between-treatment difference of -0.4 percentage points ( $95 \% \mathrm{CI}:-4.1$ to 3.3$).^{32}$ As the lower boundary of the $95 \% \mathrm{CI}$ for the difference in $\mathrm{CR}$ rates between treatment groups was greater than the prespecified value of -7 percentage points, the study hypothesis that single-dose fosaprepitant was noninferior to aprepitant was supported in the primary analysis. The fosaprepitant regimen was noninferior to the aprepitant regimen also with respect to the secondary end-point of $\mathrm{CR}$ during the delayed phase (days 2-5 postchemotherapy). For the secondary end-point of no vomiting during the overall phase, similar rates of free-vomiting patients were observed in the two treatment groups ( $73 \%$ vs $75 \%$ in the fosaprepitant and aprepitant groups, respectively). Similar rates of nausea-free patients were observed between treatment groups in the overall phase ( $53 \%$ vs $51 \%$ in the fosaprepitant and aprepitant groups, respectively). No rescue medication was used during the overall phase by a similar proportion of patients $(90 \%)$ in each treatment group.

The Saito study including 347 patients compared fosaprepitant (150 mg on day 1) to placebo, both treatment groups including also granisetron $(0.04 \mathrm{mg} / \mathrm{kg}$ intravenously on day 1$)$ and dexamethasone. ${ }^{33}$ Patients in the fosaprepitant group received a $10 \mathrm{mg}$ intravenous dose of dexamethasone on day 1 followed by a $4 \mathrm{mg}$ intravenous dose on day 2 and $8 \mathrm{mg}$ on day 3 , whereas patients in the control group received a $20 \mathrm{mg}$ intravenous dose of dexamethasone on day 1 followed by a $8 \mathrm{mg}$ intravenous dose on days 2 and 3 . The study was designed as a superiority trial, and the primary end-point was CR during the overall phase (days $1-5$ post-chemotherapy). The proportion of patients achieving $\mathrm{CR}$ in the overall phase was significantly higher in the fosaprepitant group than in the control group (64\% vs $47 \% ; P=0.001) .{ }^{33}$ In the acute and delayed phases, the rates of patients achieving CR were also significantly higher in the fosaprepitant group than in control group. The fosaprepitant regimen was significantly superior to the control regimen with respect to the secondary end-points of complete protection (defined as no emesis, no rescue antiemetics, and nausea of no more than mild severity) 
Table 3 Complete response rates from phase III clinical trials with single-dose fosaprepitant regimen in patients receiving cisplatin

\begin{tabular}{|c|c|c|c|c|c|c|}
\hline \multirow{2}{*}{$\begin{array}{l}\text { Author } \\
\text { (year) }\end{array}$} & \multirow[t]{2}{*}{ Study design } & \multirow[t]{2}{*}{$\mathbf{N}$} & \multirow{2}{*}{$\begin{array}{l}\text { Antiemetics } \\
\text { (administration schedule) }\end{array}$} & \multirow[t]{2}{*}{ Study period } & \multicolumn{2}{|l|}{ CR (\%) } \\
\hline & & & & & Fosaprepitant & Comparator \\
\hline \multirow{3}{*}{$\begin{array}{l}\text { Grunberg } \\
\text { et al }(2011)^{32}\end{array}$} & Noninferiority & 2,322 & $\mathrm{D}(4$ days $)+\mathrm{O}(\mathrm{I}$ day $)+\mathrm{FOS}(\mathrm{I}$ day $)$ & Day I & 89 & 88 \\
\hline & & & $\mathrm{D}(4$ days $)+\mathrm{O}(\mathrm{I}$ day $)+\mathrm{APR}$ (3 days) & Days 2-5 & 74 & 74 \\
\hline & & & & Days I-5 & $72^{\mathrm{a}}$ & 72 \\
\hline \multirow{3}{*}{$\begin{array}{l}\text { Saito } \\
\text { et al }(20 \mid 2)^{33}\end{array}$} & Superiority & 347 & $\mathrm{D}(3$ days $)+\mathrm{G}(\mathrm{I}$ day $)+\mathrm{FOS}$ (I day $)$ & Day I & $94^{b}$ & 81 \\
\hline & & & $\mathrm{D}(3$ days $)+\mathrm{G}(\mathrm{I}$ day $)+$ PLA (I day $)$ & Days 2-5 & $65^{b}$ & 49 \\
\hline & & & & Days I-5 & $64^{b, c}$ & 47 \\
\hline
\end{tabular}

Notes: ${ }^{a}$ Noninferiority hypothesis was proven as the lower boundary of the $95 \% \mathrm{Cl}$ for between-group difference was greater than the preset threshold $(-7 \%)$; $P<0.005$; 'primary end-point.

Abbreviations: $\mathrm{Cl}$, confidence interval; $\mathrm{CR}$, complete response (defined as no vomiting, and no rescue antiemetics); D, dexamethasone; $\mathrm{O}$, ondansetron; FOS, fosaprepitant; APR, aprepitant; G, granisetron; PLA, placebo.

and no emesis during all the study periods. In terms of nausea control, no significant differences were observed between treatment groups during all the study periods.

Both phase III trials demonstrated that a three-drug antiemetic prophylaxis containing the single-dose fosaprepitant regimen is effective and well tolerated in controlling acute and delayed CINV in patients receiving high-dose cisplatin. The clinical efficacy is consistent with the recent findings from a time-on-target PET study that compared the NK-1R occupancy in the CNS over 5 days after a single-dose infusion of $150 \mathrm{mg}$ fosaprepitant to that achieved after singledose oral administration of $165 \mathrm{mg}$ aprepitant in 16 healthy participants. ${ }^{34}$ The rates of NK-1R occupancy in the CNS after fosaprepitant at the time to peak concentration $\left(T_{\max }\right.$; approximately 30 minutes), 24, 48, and 120 hours after the dose were $100 \%, 100 \%, \geq 97 \%$, and $41 \%-75 \%$, respectively. After aprepitant, the rates of NK-1R occupancy at these time points ( $T_{\max }$; approximately 4 hours) were $\geq 99 \%$, $\geq 99 \%$, $\geq 97 \%$, and $37 \%-76 \%$, respectively. Therefore, the $150 \mathrm{mg}$ single-dose of fosaprepitant on day 1 is capable of blocking more than $90 \%$ of the NK-1Rs in the CNS for at least 48 hours after infusion, which is sufficient to control delayed CINV for 2 to 5 days after HEC.

\section{Patient acceptability}

Patients with advanced cancer have to deal with deteriorating physical health, and symptom management is of paramount importance in ensuring optimal quality of life. Therefore, advances in the prevention of CINV represent one of the major achievements in supportive care. ${ }^{15,16}$ Since most of the cytotoxic therapies are still given by an intravenous route, it is evident that there may be an indication for intravenous antiemetics not only in patients with severe mucositis, difficulty in swallowing or any gastrointestinal disturbances. Recent clinical research on CINV has demonstrated that a single injection of $150 \mathrm{mg}$ fosaprepitant is an option that is not associated with significant reduction in antiemetic control during the 5-day period following cisplatin-based chemotherapy. ${ }^{32}$ More importantly, a similar proportion of patients receiving either fosaprepitant or the conventional 3-day aprepitant regimen required antiemetic rescue medication, indicating that fosaprepitant was indeed noninferior during the overall risk period. The efficacy of the new dosage regimen of fosaprepitant was also demonstrated in a placebocontrolled trial in patients receiving cisplatin. The opportunity of replacing aprepitant with a more convenient dosing regimen is expected to improve adherence and simplify antiemetic medication schedules for patients. To our knowledge, there are no data available to date regarding acceptability of fosaprepitant in patients receiving chemotherapy. This is probably because the development of the intravenous prodrug has been hampered by the initial preference of the manufacturer for oral aprepitant. However, the important issue of patient's acceptability needs some considerations taking into account new perspectives for fosaprepitant in CINV management and research.

Recent findings indicate that, despite achievements in research on new antiemetics, CINV still remains an important clinical problem. ${ }^{35,36}$ Since preventing rather than treating CINV should be the primary goal, it is extremely important that each patient undergoing emetogenic chemotherapy receives optimal prophylaxis starting from cycle 1 of therapy. ${ }^{15,16}$ However, some physicians may be not aggressive enough in prescribing prophylaxis, ${ }^{37}$ while some patients may be nonadherent in taking their medication as prescribed and, therefore, are not able to fully benefit from antiemetic prophylaxis. ${ }^{38}$ Accurate communication between physicians and patients is particularly important to improve the control of CINV but physicians and patients may have different expectations regarding CINV management. Oncologists and oncology nurses may underestimate the incidence of delayed CINV, ${ }^{39}$ while patients undergoing chemotherapy 
are more likely than physicians to minimize their nausea and vomiting relative to other problems ${ }^{40}$ Furthermore, among the factors frequently associated with nonadherence complexity of the dosing regimen can adversely influence adherence to recommended oral therapies..$^{38} \mathrm{In}$ this scenario, the single-dose fosaprepitant regimen can help to minimize medication administration that patients must remember at home and provide the potential to decrease the number of patients receiving a suboptimal antiemetic prophylaxis.

Evidence-based recommendations for optimal management of CINV have been devised by international organizations including the American Society of Clinical Oncology (ASCO), European Society for Medical Oncology (ESMO), Multinational Association for Supportive Care in Cancer (MASCC), and National Comprehensive Cancer Network (NCCN).$^{15,16,41}$ All updated guidelines are almost identical and set out a multi-drug approach to CINV control for patients receiving HEC and MEC regimens. One exception is the combination of $\mathrm{AC}$ that is frequently used to treat a large group of cancer patients, most typically women with breast cancer. Women receiving the AC combination represent a situation with a particularly high emetic potential. ${ }^{16}$ In the light of this, the ASCO and NCCN guidelines have recently reclassified the AC combination as HEC, while the MASCC/ ESMO guidelines still label this regimen as MEC. ${ }^{15,16,41}$ However, the MASCC/ESMO guidelines separate the AC combination from other MEC. In spite of this difference, all guidelines are consistent in recommending the use of three-drug regimens including a NK-1R antagonist (ie, 3-day aprepitant or single-dose fosaprepitant regimen) for prevention of CINV caused by HEC even if the MASCC/ ESMO guidelines (that are updated only every 2 years) still recommend the use of fosaprepitant only as an alternative on day 1 of a 3-day aprepitant regimen (Table 4).
Antiemetic three-drug regimens may be inconvenient and cumbersome because continued prophylaxis with oral agents for at least 3 days is commonly recommended. It also should be pointed out that, in clinical practice, the oncologists are more likely to pay close attention to treatment guidelines for a cancer than supportive care guidelines devised to enhance the tolerability of the anticancer treatment being given. ${ }^{42}$ A recent, prospective, observational European study showed that the use of guideline-consistent CINV prophylaxis was only $55 \%$ and $46 \%$ during acute and delayed time periods, respectively, and $29 \%$ for the overall study period after cycle 1 of HEC or MEC. ${ }^{43}$ In addition, a low rate of adherence to outpatient antiemetic delayed therapy, especially for dexamethasone, has been recently reported among breast cancer patients receiving anthracycline-based chemotherapy. ${ }^{44}$ It has been suggested that one promising strategy to improve both clinical implementation of guidelines and patient's adherence is to simplify the antiemetic regimen and thereby administer all antiemetic agents as single doses before chemotherapy initiation without scheduled medication administration at home. ${ }^{28}$ In the light of this, the single-dose fosaprepitant regimen not only can allow shorter, more convenient dosing schedule for the NK-1R antagonist but also retain the potential of achieving dexamethasone exposure to continue for multiple days even after a single corticosteroid dose. It has been shown that aprepitant-induced inhibition of dexamethasone metabolism can cause an extended exposure to dexamethasone that can provide protection for the entire period of major risk for acute and delayed CINV. ${ }^{28}$ Furthermore, the feasibility of a dexamethasone-sparing strategy could be maximized by the use of single-dose palonosetron, a long-acting 5- $\mathrm{HT}_{3} \mathrm{R}$ antagonist with an halflife of approximately 40 hours, which can obtain an extended 5-HT antagonist effect. ${ }^{45}$ Recent phase III trials demonstrated

Table 4 Recommended antiemetic regimens for HEC and AC-containing regimens based on the major international guidelines

\begin{tabular}{|c|c|c|c|}
\hline \multirow[t]{2}{*}{ Guidelines } & \multirow[t]{2}{*}{ Emetic risk } & \multicolumn{2}{|l|}{ Recommended antiemetic therapy } \\
\hline & & Day I & Beyond day I \\
\hline $\mathrm{ASCO}^{15}$ & $\mathrm{High}^{\mathrm{a}}$ & $5-\mathrm{HT}_{3} \mathrm{RA}+\mathrm{NK}-\mathrm{IRA}{ }^{\mathrm{b}}+$ Dexamethasone & Dexamethasone + Aprepitant $^{d}$ \\
\hline \multirow[t]{2}{*}{ MASCC/ESMO' ${ }^{16}$} & High & $5-\mathrm{HT}_{3} \mathrm{RA}+\mathrm{NK}-\mathrm{IRA} \mathrm{A}^{\mathrm{c}}+$ Dexamethasone & Dexamethasone + Aprepitant \\
\hline & Moderate (AC combinations) & $5-\mathrm{HT}_{3} \mathrm{RA}^{\mathrm{e}}+\mathrm{NK}-\mathrm{IRA} \mathrm{A}^{\mathrm{c}}+$ Dexamethasone & Aprepitant \\
\hline $\mathrm{NCCN}^{41}$ & High $^{\mathrm{a}}$ & $\begin{array}{l}\text { 5- } \mathrm{HT}_{3} \mathrm{RA} \text { (palonosetron preferred) }+ \\
\mathrm{NK}-\mathrm{IRA}^{\mathrm{b}}+\text { Dexamethasone } \pm \text { lorazepam } \pm \\
\mathrm{H}_{2} \text { blocker or proton pump inhibitor }\end{array}$ & $\begin{array}{l}\text { Dexamethasone }+ \text { Aprepitant }{ }^{d} \pm \\
\text { lorazepam } \pm \mathrm{H}_{2} \text { blocker or proton } \\
\text { pump inhibitor }\end{array}$ \\
\hline
\end{tabular}

Notes: äoth ASCO and NCCN guidelines have reclassified the AC combination as highly emetogenic chemotherapy; bintravenous fosaprepitant $150 \mathrm{mg}$ or oral aprepitant $125 \mathrm{mg}$; intravenous fosaprepitant II5 mg or oral aprepitant $125 \mathrm{mg}$; ' when aprepitant is used on day I; if an NK-IRA is not available for the AC combination, palonosetron plus dexamethasone is the preferred $5-\mathrm{HT}_{3} \mathrm{RA}$.

Abbreviations: HEC, highly emetogenic chemotherapy; AC, anthracycline and cyclophosphamide; 5- $\mathrm{HT}_{3} \mathrm{RA}, 5-\mathrm{HT}_{3}$ receptor antagonist; NK-IRA, NK-I receptor antagonist; ASCO, American Society of Clinical Oncology; MASCC/ESMO, Multinational Association of Supportive Care in Cancer/European Society for Medical Oncology; NCCN, National Comprehensive Cancer Network. 
that palonosetron plus single-dose dexamethasone administered either before a broad range of MEC or the high-risk combination of $\mathrm{AC}$ provided protection against CINV in the overall phase, which was noninferior to palonosetron plus the conventional 3-day dexamethasone. ${ }^{46,47}$ On the basis of these evidences, the single-dose fosaprepitant regimen can contribute not only to enhance clinical implementation of guidelines but also to assess, when studied in combination with palonosetron, optimal schedules for use of dexamethasone in HEC setting. Moreover, results from trials evaluating the efficacy of single-dose fosaprepitant as a rescue therapy for breakthrough CINV are eagerly awaited.

The benefit of using a new, higher-cost agent as part of the CINV prophylaxis should be considered in the context of an increasing need to find ways to allocate limited resources in cancer care. ${ }^{48}$ Therefore, clinical practice guidelines should include cost-effectiveness information in order to enable guideline end-users to make decisions that account for real-world constraints while ensuring the highest quality care of CINV. ${ }^{49}$ Direct costs of uncontrolled CINV rely on the need for rescue medication, unscheduled office visits, and emergency room admissions. ${ }^{35}$ In addition, reduced productivity at work or lost workdays for patients and/or caregivers may represent indirect costs resulting from uncontrolled CINV. ${ }^{36}$ Therefore, if the total savings achieved from lowering the rate of uncontrolled, delayed CINV outweigh the higher acquisition cost of a new drug, prophylaxis with this agent in clinical practice should be considered economically justified..$^{50}$ Of interest, the use of aprepitant in CINV control was shown to be cost-effective in two European analyses, ${ }^{51,52}$ but a US study suggested that aprepitant provides only modest incremental benefit compared with conventional two-drug regimens against CINV caused by HEC. ${ }^{53}$ Nevertheless, the investigators also stated that routine use of aprepitant may be cost-effective in clinical settings where the likelihood of delayed CINV or the cost of rescue antiemetics is high. Economic analyses across countries, therefore, should evaluate the impact of newer antiemetic strategies including the single-dose fosaprepitant regimen on healthcare resource use secondary to poorly controlled CINV.

\section{Conclusions}

Provocative data from a randomized noninferiority trial demonstrate that a single dose of intravenous fosaprepitant $150 \mathrm{mg}$ on day 1 offers similar protection as the 3-day oral regimen of aprepitant in patients who are scheduled to receive cisplatin. The new dosage regimen of fosaprepitant can provide a simplified treatment option that maintains high protection while ensuring adherence to scheduled antiemetic medication throughout most of the 5-day period encompassing the major risk for CINV. The single-dose regimen also retains the potential to make a meaningful contribution to CINV research devoted to the improvement of a patient's quality of life.

\section{Disclosures}

The authors have no conflicts of interest to declare.

\section{References}

1. Cleeland CS, Allen JD, Roberts SA, et al. Reducing the toxicity of cancer therapy: recognizing needs, taking action. Nat Rev Clin Oncol. 2012;9(8):471-478.

2. Hesketh PJ. Chemotherapy-induced nausea and vomiting. $N$ Engl J Med. 2008;358(23):2482-2494.

3. Schwartzberg LS. Chemotherapy-induced nausea and vomiting: clinician and patient perspectives. J Support Oncol. 2007;5(Suppl 1):5-12.

4. Roscoe JA, Morrow GR, Aapro MS, Molassiotis A, Olver I. Anticipatory nausea and vomiting. Support Care Cancer. 2011;19(10):1533-1538.

5. Nevidjon B, Chaudhary R. Controlling emesis: evolving challenges, novel strategies. J Support Oncol. 2010;8(Suppl 2):1-10.

6. Trigg ME, Higa GM. Chemotherapy-induced nausea and vomiting: antiemetic trials that impacted clinical practice. J Oncol Pharm Pract. 2010;16(4):233-244.

7. Hesketh PJ, Van Belle S, Aapro M, et al. Differential involvement of neurotransmitters through the time course of cisplatin-induced emesis as revealed by therapy with specific receptor antagonists. Eur J Cancer. 2003;39(8):1074-1080.

8. Prommer E. Aprepitant (EMEND): the role of substance $P$ in nausea and vomiting. J Pain Palliat Care Pharmacother. 2005;19(3):31-39.

9. Smith DB, Newlands ES, Rustin GJ, et al. Comparison of ondansetron and ondansetron plus dexamethasone as antiemetic prophylaxis during cisplatin-containing chemotherapy. Lancet. 1991;338(8765):487-490.

10. Hesketh PJ, Harvey WH, Harker WG, et al. A randomized, double-blind comparison of intravenous ondansetron alone and in combination with intravenous dexamethasone in the prevention of high-dose cisplatininduced emesis. J Clin Oncol. 1994;12(3):596-600.

11. Hesketh PJ, Grunberg SM, Gralla RJ, et al. The oral neurokinin-1 antagonist aprepitant for the prevention of chemotherapy-induced nausea and vomiting: a multinational, randomized, double-blind, placebocontrolled trial in patients receiving high-dose cisplatin - the Aprepitant Protocol 052 Study Group. J Clin Oncol. 2003;21(22):4112-4119.

12. Poli-Bigelli S, Rodrigues-Pereira J, Carides AD, et al. Addition of the neurokinin-1 receptor antagonist aprepitant to standard antiemetic therapy improves control of chemotherapy induced nausea and vomiting: results from a randomized, double-blind, placebo-controlled trial in Latin America. Cancer. 2003;97(12):3090-3098.

13. Warr DG, Hesketh PJ, Gralla RJ, et al. Efficacy and tolerability of aprepitant for the prevention of chemotherapy-induced nausea and vomiting in patients with breast cancer after moderately emetogenic chemotherapy. J Clin Oncol. 2005;23(12):2822-2830.

14. Hargreaves R, Ferreira JC, Hughes D, et al. Development of aprepitant, the first neurokinin-1 receptor antagonist for the prevention of chemotherapyinduced nausea and vomiting. Ann N Y Acad Sci. 2011;1222:40-48.

15. Basch E, Prestrud AA, Hesketh PJ, et al. Antiemetics: American Society of Clinical Oncology clinical practice guideline update. J Clin Oncol. 2011;29(31):4189-4198.

16. Roila F, Herrstedt J, Aapro M, et al. Guideline update for MASCC and ESMO in the prevention of chemotherapy- and radiotherapy-induced nausea and vomiting: results of the Perugia consensus conference. Ann Oncol. 2010;21(Supp1 5):v232-v243.

17. Bergstrom M, Hargreaves RJ, Burns HD, et al. Human positron emission tomography studies of brain neurokinin 1 receptor occupancy by aprepitant. Biol Psychiatry. 2004;55(10):1007-1012. 
18. Huskey SE, Luffer-Atlas D, Dean BJ, McGowan EM, Feeney WP, Chiu SH. Substance P receptor antagonist I: conversion of phosphoramidate prodrug after i.v. administration to rats and dogs. Drug Metab Dispos. 1999;27(11):1367-1373.

19. Sanchez RI, Wang RW, Newton DJ, et al. Cytochrome P450 3A4 is the major enzyme involved in the metabolism of the substance $P$ receptor antagonist aprepitant. Drug Metab Dispos. 2004;32(11):1287-1292.

20. Colon-Gonzales F, Kraft WK. Pharmacokinetic evaluation of fosaprepitant dimeglumine. Expert Opin Drug Metab Toxicol. 2010;6(10): 1277-1286.

21. Lasseter KC, Gambale J, Jin B, et al. Tolerability of fosaprepitant and bioequivalency to aprepitant in healthy subjects. $J$ Clin Pharmacol. 2007;47(7):834-840.

22. Cocquyt V, Van Belle S, Reinhardt RR, et al. Comparison of L-758,298, a prodrug for the selective neurokinin-1 antagonist, L754,030, with ondansetron for the prevention of cisplatin-induced emesis. Eur $J$ Cancer. 2001;37(7):835-842.

23. Van Belle S, Lichinitser MR, Navari RM, et al. Prevention of cisplatininduced acute and delayed emesis by the selective neurokinin-1 antagonists, L-754,298 and MK-869: a randomized controlled trial. Cancer. 2002;94(11):3032-3041.

24. Marbury TC, Jin B, Panebianco D, et al. Lack of effect of aprepitant or its prodrug fosaprepitant on QTc intervals in healthy subjects. Anesth Analg. 2009;109(2):418-425.

25. dos Santos LV, Souza FH, Brunetto AT, Sasse AD, da Silveira Nogueira Lima JP. Neurokinin-1 receptor antagonists for chemotherapyinduced nausea and vomiting: a systematic review. $J$ Natl Cancer Inst. 2012;104(17):1280-1292.

26. Chawla SP, Grunberg SM, Gralla RJ, et al. Establishing the dose of the oral NK1 antagonist aprepitant for the prevention of chemotherapyinduced nausea and vomiting. Cancer. 2003;97(9):2290-2300.

27. Majumdar AK, Howard L, Goldberg MR, et al. Pharmacokinetics of aprepitant after single and multiple oral doses in healthy volunteers. J Clin Pharmacol. 2006;46(3):291-300.

28. Grunberg SM, Dugan M, Muss H, et al. Effectiveness of a single-day three-drug regimen of dexamethasone, palonosetron, and aprepitant for the prevention of acute and delayed nausea and vomiting caused by moderately emetogenic chemotherapy. Support Care Cancer. 2009;17(5):589-594.

29. Herrington JD, Jaskiewicz AD, Song J. Randomized, placebo-controlled, pilot study evaluating aprepitant single dose plus palonosetron and dexamethasone for the prevention of acute and delayed chemotherapyinduced nausea and vomiting. Cancer. 2008;112(9):2080-2087.

30. Langford P, Chrisp P. Fosaprepitant and aprepitant: an update of the evidence for their place in the prevention of chemotherapy-induced nausea and vomiting. Core Evid. 2010;5:77-90.

31. Shmoll HJ, Aapro MS, Poli-Bigelli S, et al. Comparison of an aprepitant regimen with a multiple-day ondansetron regimen, both with dexamethasone, for antiemetic efficacy in high-dose cisplatin treatment. Ann Oncol. 2006;17(6):1000-1006.

32. Grunberg S, Chua D, Maru A, et al. Single-dose fosaprepitant for prevention of chemotherapy-induced nausea and vomiting associated with cisplatin therapy: randomized, double-blind study protocol-EASE. J Clin Oncol. 2001;29(11):1495-1501.

33. Saito H, Yoshizawa H, Yoshimori K, et al. Efficacy and safety of a singledose fosaprepitant in the prevention of chemotherapy-induced nausea and vomiting in patients receiving high-dose cisplatin: a multicentre, randomized, double-blind, placebo-controlled phase 3 trial. Ann Oncol. 2013;24(4):1067-1073.

34. Van Laere K, De Hoon J, Bormans G, et al. Equivalent dynamic human brain NK1-receptor occupancy following single-dose i.v. fosaprepitant vs oral aprepitant as assessed by PET imaging. Clin Pharmacol Ther. 2012;92(2):243-250.

35. Burke TA, Wisniewski T, Ernst FR. Resource utilization and costs associated with chemotherapy-induced nausea and vomiting (CINV) following highly or moderately emetogenic chemotherapy administered in the US outpatient hospital setting. Support Care Cancer. 2011;19(1):131-140
36. Haiderali A, Menditto L, Good M, Teitelbaum A, Wegner J. Impact on daily functioning and indirect/direct costs associated with chemotherapy-induced nausea and vomiting (CINV) in a US population. Support Care Cancer. 2011;19(6):843-851.

37. Gomez DR, Liao K-P, Giordano S, Nguyen H, Smith BD, Elting LS. Adherence to national guidelines for anti-emesis prophylaxis in patients undergoing chemotherapy for lung cancer. Cancer. 2013;119(7): $1428-1436$.

38. Ruddy K, Mayer E, Partridge A. Patient adherence and persistence with oral anticancer treatment. CA Cancer J Clin. 2009;59(1):56-66.

39. Grunberg SM, Deuson RR, Mavros P, et al. Incidence of chemotherapy-induced nausea and emesis after modern antiemetics. Cancer. 2004;100(10):2261-2268.

40. Salsman JM, Grunberg SM, Beaumont JL, et al. Communicating about chemotherapy-induced nausea and vomiting: a comparison of patient and provider perspectives. J Natl Compr Canc Netw. 2012;10(2): $149-157$.

41. National Comprehensive Cancer Network: Clinical Practice Guidelines in Oncology: Antiemesis, version 1. 2013. Available from: http://www. nccn.org/professional/physician_gls/PDF/antiemesis.pdf. Accessed February 8, 2013.

42. Grunberg S, Ettinger DS, Hauber AB, et al. How familiar are oncologists with therapeutic care and supportive care guidelines [abstract]? Support Care Cancer. 2008; 16:631-632.

43. Aapro M, Molassiotis A, Dicato M, et al. The effect of guidelineconsistent antiemetic therapy on chemotherapy-induced nausea and vomiting (CINV): the Pan European Emesis Registry (PEER). Ann Oncol. 2012;23(8):1986-1992.

44. Chan A, Low XH, Yap KY. Assessment of the relationship between adherence with antiemetic drug therapy and control of nausea and vomiting in breast cancer patients receiving anthracycline-based chemotherapy. J Manag Care Pharm. 2012;18(5):385-394.

45. Celio L, Agustoni F, Testa I, Dotti K, De Braud F. Palonosetron: an evidence-base choice in prevention of nausea and vomiting induced by moderately emetogenic chemotherapy. Tumori. 2012;98(3):279-286.

46. Celio L, Frustaci S, Denaro A, et al. Palonosetron in combination with 1-day versus 3-day dexamethasone for prevention of nausea and vomiting following moderately emetogenic chemotherapy: a randomized, multicenter, phase III trial. Support Care Cancer. 2011;19(8):1217-1225.

47. Aapro M, Fabi A, Nolè F, et al. Double-blind, randomised, controlled study of the efficacy and tolerability of palonosetron plus dexamethasone for 1 day with or without dexamethasone on days 2 and 3 in the prevention of nausea and vomiting induced by moderately emetogenic chemotherapy. Ann Oncol. 2010;21(5):1083-1088.

48. Smith TJ, Hillner BE. Bending the cost curve in cancer care. $N$ Engl J Med. 2011;364(21):2060-2065.

49. Basch E, Somerfield MR, Partridge A, Schnipper L, Lyman GH. Commentary: Should cost and comparative value of treatments be considered in clinical practice guidelines? J Oncol Pract. 2011;7(6): 398-401.

50. Tina Shih Y-C, Ying X, Elting LS. Costs of uncontrolled chemotherapyinduced nausea and vomiting among working-age cancer patients receiving highly or moderately emetogenic chemotherapy. Cancer. 2007;110(3):678-685.

51. Lordick F, Ehlken B, Ihbe-Heffinger A, et al. Health outcomes and cost-effectiveness of aprepitant in outpatient receiving antiemetic prophylaxis for highly emetogenic chemotherapy in Germany. Eur $J$ Cancer. 2007;43(2):299-307.

52. Annemans L, Strens D, Lox E, Petit C, Malonne H. Cost-effectiveness analysis of aprepitant in the prevention of chemotherapy-induced nausea and vomiting in Belgium. Support Care Cancer. 2008;16(8): 905-915.

53. Moore S, Tumeh J, Wojtanowski S, Flowers C. Cost-effectiveness of aprepitant for the prevention of chemotherapy-induced nausea and vomiting associated with highly emetogenic chemotherapy. Value Health. 2007;10(1):23-31. 
Patient Preference and Adherence

Dovepress

\section{Publish your work in this journal}

Patient Preference and Adherence is an international, peer-reviewed, open access journal focusing on the growing importance of patient preference and adherence throughout the therapeutic continuum. Patient satisfaction, acceptability, quality of life, compliance, persistence and their role in developing new therapeutic modalities and compounds to

optimize clinical outcomes for existing disease states are major areas of interest. This journal has been accepted for indexing on PubMed Central. The manuscript management system is completely online and includes a very quick and fair peer-review system. Visit http://www.dovepress.com/ testimonials.php to read real quotes from published authors.

Submit your manuscript here: http://www.dovepress.com/patient-preference-and-adherence-journal 